\title{
CCR2 Genetic Polymorphism And Its Potential Effect On HIV Acquisition In A Population Of Children Living In The Northern Region Of Cameroon
}

This article was published in the following Dove Press journal:

The Application of Clinical Genetics

Marie Nicole Ngoufack ${ }^{1,2}$

Céline Nguefeu Nkenfou ${ }^{2,3}$

Barbara Atogho Tiedeu (D)

Linda Chapdeleine Mekue

Mouafo $^{2,4}$

Beatrice Dambaya ${ }^{2,5}$

Elvis Ndukong Ndzi ${ }^{2,4}$

Charles Kouanfack ${ }^{6}$

Georges Nguefack-Tsague (iD) ${ }^{7}$

Wilfred Fon Mbacham (D)

Alexis Ndjolo ${ }^{2}$

'Department of Biochemistry, Faculty of Science, University of Yaoundé I, Yaoundé, Cameroon; ${ }^{2}$ Systems Biology, Chantal Biya' International Reference Centre for Research on HIV and AIDS Prevention and Management (CBIRC), Yaoundé, Cameroon; ${ }^{3}$ Department of Biology, Higher Teachers' Training College, University of Yaoundé I, Yaoundé, Cameroon; ${ }^{4}$ Department of Biochemistry, Faculty of Science, University of Dschang, Dschang, Cameroon;

${ }^{5}$ Department of Animal Sciences, Faculty of Science, University of Yaoundé I, Yaoundé, Cameroon; 'Department of Public Health, Faculty of Medicine and Pharmaceutical Sciences, University of Dschang, Dschang, Cameroon; ${ }^{7}$ Department of Public Health, Faculty of Medicine and Biomedical Sciences, University of Yaoundé I, Yaoundé, Cameroon

Correspondence: Céline Nguefeu Nkenfou Laboratory of Systems Biology "Chantal Biya" International Reference Centre for Research on HIV and AIDS Prevention and Management (CBIRC), P.O. Box 3077,

Messa, Yaoundé, Cameroon

Tel +237675 573519

Fax +237222315456

Email nkenfou@yahoo.com
Background and objectives: The association of chemokine receptor-2 (CCR2) polymorphism with HIV transmission or disease progression remains highly controversial. The role of CCR2-64I allele in HIV infection may differ from one population to another because of their genetic background. The objectives of this study were to characterize the CCR2 genetic polymorphism and to determine its potential effect in HIV acquisition in children living in the Northern Region of Cameroon.

Materials and methods: A cross-sectional study was carried out in five health facilities in the Northern region of Cameroon. DNA was extracted from the Buffy coat of each participant using the QIAamp ${ }^{\circledR}$ DNA mini kit. The DNA extract was then subjected to polymorphic analyses. CCR2 genotypes were analyzed by polymerase chain reaction (PCR) and restriction fragment length polymorphism (RFLP). The Chi-Squared test was used for the assessment of the Hardy-Weinberg equilibrium.

Results: A total of 134 children under 15 years comprised of 38 HIV-exposed infected (28.36\%) and 96 HIV-exposed un-infected (71.64\%) participants were recruited. Prevalences of $44.78 \%$ wild type homozygous, $48.52 \%$ heterozygous and $6.7 \%$ mutant homozygous alleles were found in the overall population. An allelic frequency of $29.69 \%$ for the mutant allele CCR2-64I was found in HIV-exposed un-infected individuals as compared to $34.21 \%$ in HIV-infected children $(\mathrm{p}=0.47)$.

Conclusion: The CCR2-64I allele is relatively common in the Northern Region of Cameroon, with a similar distribution among HIV-exposed un-infected and infected children. As this allele alone does not seem to confer protection against HIV-1 infection, further studies using genotype-combination of CCR2 polymorphism and other single nucleotide polymorphisms would be of great relevance in both HIV prevention and novel therapeutic strategies.

Keywords: HIV acquisition, CCR2 gene, pediatric population

\section{Introduction}

Of the estimated 36.9 million people living with HIV worldwide, approximately 1.8 million are children under 15 years of age ${ }^{1,2}$ of whom $90 \%$ live in Africa. ${ }^{3}$ This alarming situation is partly explained by the fact that sub-Saharan Africa is home to nearly $90 \%$ of pregnant women living with HIV. Because the immune system of children is not fully developed, their infection is more severe than in adults. They may experience the same common pediatric infections as HIV-negative children but 
cannot fight them as effectively. Cameroon is among the 22 countries with a high burden of HIV mother-to-child transmission (MTCT). ${ }^{4}$ A recent study carried out in Cameroon showed differential HIV prevalence according to the regions, ranging from $6.3 \%$ in the Southern Region to $1.5 \%$ in the Far North Region. The Northern Region, dominated by the Fulbe people, has one of the lowest prevalence rates (1.6\%) among individuals aged from 15 to 49 years. The prevalence in children from 0 to 14 years was $0.2 \%{ }^{5}$ However, this region has the second highest rate of MTCT (7.8\%). The prevalence of HIV among pregnant women in Cameroon is $5.7 \%$, which is above the general level found among people aged from 15-49 (3.4\%). Early Infant Diagnosis (EID) data collected from the Reference Laboratories database and Point of Care devices in Cameroon showed a national HIV positivity rate of 5\% in 2017 for children exposed to HIV. In the Northern Region of Cameroon, this positivity rate is much higher $(7.8 \%)^{6}$ More than $90 \%$ of HIV infections in children result from MTCT. Several maternal factors, including low CD4+ lymphocyte counts, high viral load, immune response, advanced disease status, smoking and drug abuse have been implicated in an increased risk of this transmission. However, the molecular mechanisms of HIV-1 MTCT and differential infection in neonates/infants remain poorly understood.

Studies have shown that chemokine and chemokine receptors involved in the modulation of innate and adaptive immune processes also act as co-receptors to HIV. They help viral attachment and entry into host cells. Polymorphisms in genes encoding chemokine such as stromal cell derived factor $1(S D F 1)$ and chemokine receptors such as $\mathrm{C}-\mathrm{C}$ motif chemokine receptor 2 (CCR2) have been implicated in differential outcomes of HIV infection and disease progression. ${ }^{7} C C R 2-64 I$ polymorphism is one of the important variations that modulate this infection. ${ }^{8}$ This is by a single nucleotide substitution of a valine residue for an isoleucine at position 64 in the CCR2 receptor. ${ }^{9}$ It occurs in a transmembrane segment of the receptor and is unlikely to significantly alter the structure or function of the CCR 2 receptor. ${ }^{10}$ The effect of chemokine and chemokine receptor genetic polymorphisms like CCR2-64I associated with HIV-1 transmission and/or rate of disease progression in infected subjects remains highly controversial. $^{11-13}$ Several studies have investigated whether the CCR2-Val64Ile polymorphism affects susceptibility to Human Immune deficiency Virus type-1 (HIV-1), but the results have been inconclusive. The meta-analysis of Mouafo et $\mathrm{al}^{11}$ clearly showed this controversy as they revealed a protective role of CCR2-64I on MTCT using infant and maternal samples from population in Malawi, South Africa and Uganda. On the contrary, CCR2-64I was found to have no effect on MTCT in mothers in Western Kenya. A protective role of the allele was found in in a study carried out by Mangano et al. ${ }^{14}$ Another study by Mabuka et $\mathrm{al}^{15}$ reported a partial protection while others found that this allele seemed not to confer protection against HIV infection. ${ }^{16,17}$ The infant's genetics can alter the risk for HIV-1 infection. To our knowledge, this is the first study to report the frequencies of CCR2 chemokine receptor variants in a pediatric population in this area, considering their ethnic background. The study is intended to determine the distribution of the CCR2 polymorphism and its potential effect on HIV acquisition in children living in the Northern Region of Cameroon. Identifying genetic susceptibility variants could help in predicting disease course.

\section{Materials And Methods \\ Patient Selection}

A total of 134 children under 15 years, comprised of 38 HIV-infected and $96 \mathrm{HIV}$-exposed un-infected individuals, were recruited from August 2015 to October 2016. Five (5) $\mathrm{mL}$ of total blood were collected in EDTA tubes from each participant. The plasma was used for HIV diagnosis and the Buffy coat for genomic DNA extraction prior to genotyping. Only children whose mothers provided parental consent were enrolled, and a questionnaire was administered to them. The parental consent was written. Also, this study was conducted in accordance to the Declaration of Helsinki.

The study protocol was reviewed and approved by the Cameroon National Ethical Committee for Research on Human Health (N²013/11/375/L/CNERSH/SP). Permission to collect and analyze samples was obtained through authorizations given by the Ministry of Public Health $(\mathrm{MoH})$ and the Directors of the different health facilities.

\section{Setting}

The study was carried out in five health facilities of the Northern region of Cameroon: the Garoua Regional Hospital; the District Hospitals of Guider and Figuil, the Hospitals of Lainde and Djamboutou.

\section{HIV Testing}

For children older than 18 months, the detection of HIV antibodies was performed using the Determine HIV1/2 test 
(Alere Medical Co., Ltd. 357 Matsuhidai, Matsudo-shi, Chiba). For positive samples, a confirmation was done with the OraQuick test (OraSure Technologies, Inc. Bethlehem). For children less than 18 months, HIV diagnosis was performed by PCR using Abbott qualitative Real-time PCR kits (Abbott TM mSample Preparation System DNA» Promega Corporation. Madison WI 53711 USA). EID is an important step to link infants infected with HIV to ART and to reduce infant morbidity and mortality. The Abbott qualitative Realtime PCR was used in this study for the detection of HIV-1 nucleic acids. The lower limit of detection of the test is 2500 copies $/ \mathrm{mL}$. When the number of copies is $\geq 2500$ copies $/ \mathrm{mL}$, the test detects the presence of nucleic acids and the result is "Detected." If the number is below 2500 copies/mL, ${ }^{18,19}$ the test does not detect nucleic acids and the result is "Not detected." This is a limit and to overcome this limit, children are followed up until 18 months for a negative serology

\section{DNA Extraction}

Genomic DNA was extracted from the buffy coat using the QIAamp $^{\circledR}$ DNA mini kit (Qiagen, 40724 Hilden, Germany) according to the manufacturer's instructions. The extract was then re-suspended in $200 \mu \mathrm{l} \mathrm{AE} \mathrm{buffer}$ (Qiagen, 40724 Hilden, Germany) and stored at $-20^{\circ} \mathrm{C}$ for further analyses.

\section{CCR2 Genotyping}

Polymerase Chain Reaction and Restriction Fragment Length Polymorphism (PCR-RFLP) were used for CCR2 genotyping.
The following pairs of primers were used for the PCR: Forward 5'-CTTCATCATCCTCCTGACAATCG-3', reverse 5'-GACCAGCCCCAAGTTGACTATC-3') as previously described. ${ }^{20}$ A 380 base pair (bp) fragment was amplified in a $25 \mu \mathrm{L}$ volume reaction containing $0.2 \mu \mathrm{M}$ of each primer, $1 \mathrm{X}$ PCR buffer containing $\mathrm{MgCl}_{2}, 200 \mu \mathrm{M}$ of each dNTP (Thermo Scientific), 0.625 Units of Taq polymerase (Roche Diagnostic, One Lambda, USA) and $5 \mu \mathrm{L}(2-5 \mathrm{ng})$ of genomic DNA. The reaction mix was subjected to amplification using the following conditions: initial denaturation at $95^{\circ} \mathrm{C}$ for $3 \mathrm{~min}$, followed by 40 cycles of denaturation at $94^{\circ} \mathrm{C}$ for $30 \mathrm{~S}$, annealing at $63^{\circ} \mathrm{C}$ for $30 \mathrm{~S}$, extension at $72^{\circ} \mathrm{C}$ for $30 \mathrm{~S}$ and a final extension at $72^{\circ} \mathrm{C}$ for $10 \mathrm{~min}$. A $10 \mu \mathrm{L}$ volume of the PCR product was digested overnight using 5 Units of FokI restriction enzyme (New England Biolabs). The digested product was separated on $2 \%$ agarose gel, stained with ethidium bromide and visualized under UV light, then photographed. The mutated allele (CCR2-64I) was susceptible to FokI restriction digestion. The PCR product was then cleaved, giving rise to two fragments of $215 \mathrm{bp}$ and $165 \mathrm{bp}$. The wild type allele (CCR2-64V) lacked the sequence recognised by FokI, leaving the $380 \mathrm{bp}$ PCR product undigested. Two fragments of 215 and $165 \mathrm{bp}$ were seen in the gel if a person was homozygous for the mutation. For the heterozygous, there were three fragments on the gel at $380 \mathrm{bp}, 215 \mathrm{bp}$ and $165 \mathrm{bp}$ (Figure 1). Only one fragment was seen at $380 \mathrm{bp}$ if the $C C R 2$ gene fragment did not have the mutation and the person was of a wild type.

\section{Statistical Analyses}

For the calculation of allelic frequencies, the following formula was used: $\mathrm{F}=(\mathrm{h}+2 \mathrm{H}) / 2 \mathrm{~N}$, where $\mathrm{F}$ is the frequency, $\mathrm{H}$ is

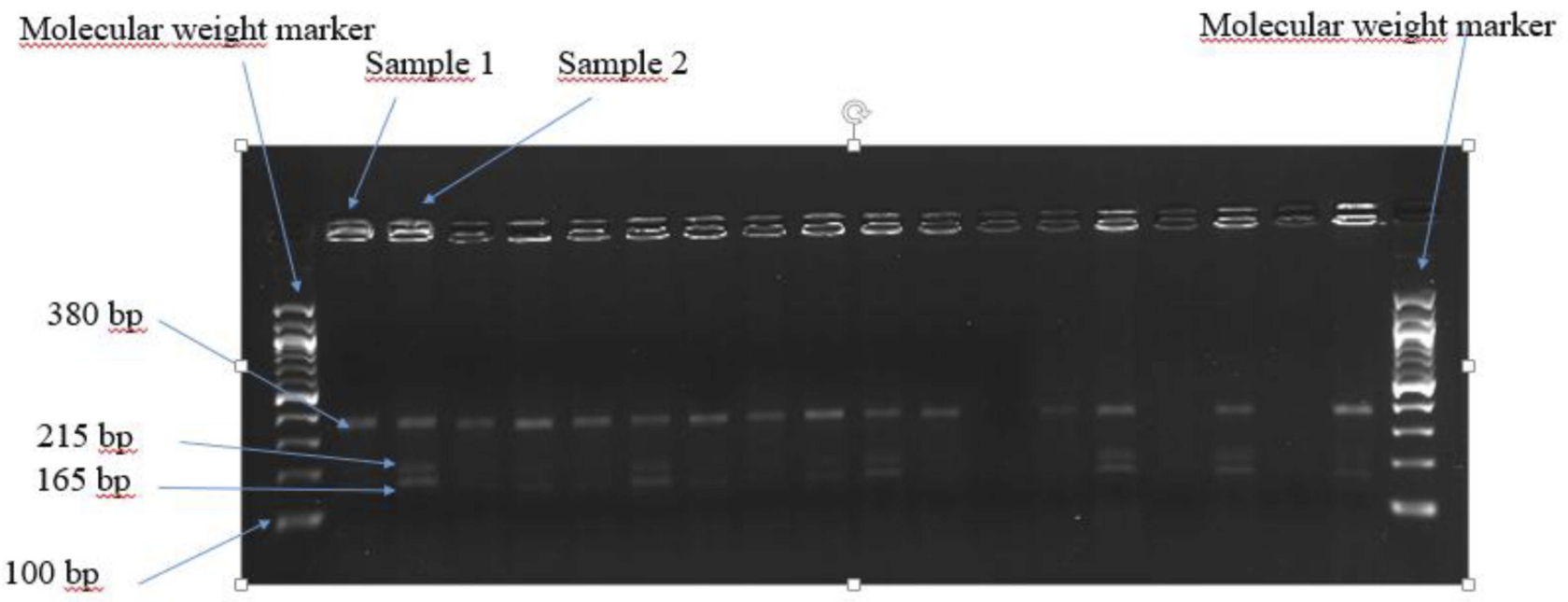

Figure I Electrophoregram showing the polymorphism of CCR2 641 in selected participants. Sample I: Wild type homozygous. Sample 2: Heterozygous. 
the number of samples with a homozygous mutation genotype, $\mathrm{h}$ is the number with a heterozygous mutation genotype and $\mathrm{N}$ the total number of samples. Hardy Weinberg Equilibrium (HWE) was tested using Chi-Squared. The allelic frequencies of the CCR2-64I and CCR2-64V alleles were compared between the HIV positive and negative groups.

\section{Results}

\section{Demographic Characteristics}

To determine the distribution of CCR2-64I genetic variants, 134 participants under 15 years were recruited. Among them were 64 girls $(47.76 \%)$ and 70 boys $(52.24 \%)$.

\section{Genotyping}

The prevalences of $44.78 \%$ for the G/G genotype (homozygous wild type genotype), $48.51 \%$ for the G/A genotype (heterozygous genotype) and $6.71 \%$ for the A/A genotype (homozygous mutant genotype) were identified in our study population. This is the first time the prevalence of the CCR2 gene variant has been described in a pediatric group in the Northern Region of Cameroon. Overall, 39.48\% HIV-positive (15/38) and 46.88\% HIV-negative (45/96) were wild type CCR2, 52.63\% HIV-positive (20/38) and 46.88\% HIV-negative (45/96) were heterozygous CCR2-64I carriers and 7.89\% HIV-positive (3/38) and 6.25\% HIV-negative (6/96) were homozygous mutants for CCR2-64I (Table 1). The allelic frequency of CCR2-64I was $29.69 \%$ in the HIV negative group and $34.21 \%$ in the HIV-positive group (Table 2). There were no significant differences between the two groups with respect to the distribution of CCR2-64I ( $\mathrm{p}=0.47)$.

The Hardy-Weinberg Equilibrium (HWE) analysis revealed that all genetic variants for CCR2-64I in the studied population were in equilibrium $(\mathrm{p}=0.09)$.

\section{Allelic Frequency Of CCR2-64I And HIV Status}

Allelic frequencies according to the HIV status are presented in Table 2.
Table 2 Allelic Frequencies And HIV Status In The Study Population

\begin{tabular}{|c|c|c|c|c|}
\hline $\begin{array}{l}\text { CCR2 Gene } \\
\text { Alleles }\end{array}$ & $\begin{array}{l}\text { HIV } \\
\text { Infected } \\
(\%)\end{array}$ & $\begin{array}{l}\text { HIV Un- } \\
\text { Infected (\%) }\end{array}$ & $\begin{array}{l}\text { Total } \\
\text { (\%) }\end{array}$ & P-value \\
\hline $\begin{array}{l}\text { Mutant type } \\
\text { (CCR2-64I) }\end{array}$ & 34.21 & 29.69 & 30.97 & $P=0.47$ \\
\hline $\begin{array}{l}\text { Wild type } \\
\text { (CCR2-64V) }\end{array}$ & 65.79 & 70.31 & 69.03 & \\
\hline
\end{tabular}

The allelic frequency of CCR2-64I in HIV-infected children (34.21\%) was not significantly higher than that observed in HIV-exposed un-infected children (29.69\%) with $\mathrm{p}=0.47$. This suggests that the CCR2-64I allele seems not to confer protection against HIV infection in children of the Northern Region of Cameroon.

\section{Discussion}

In this study, the Abbott qualitative Real-time PCR was used for the detection of HIV-1 nucleic acids. Infants infected with HIV usually have very high HIV-1 RNA levels without any treatment. But given the fact that children receive nevirapine at birth that may reduce viremia, a sample with "Not detected" result cannot be presumed negative for HIV-1. It is well known that genetic background has an impact on HIV infection and progression to AIDS, but little is known about the genetic background of Cameroon Northern Region pediatric population in relation to this disease. The Northern Region of Cameroon is dominated by the Fulbe people. In this study, 134 participants were enrolled. Among them were $38 \mathrm{HIV}$ infected (28.36\%) and $96 \mathrm{HIV}$ un-infected (71.64\%) children. CCR2-64I is relatively common in this population. The CCR2$64 I$ variant occurred with a frequency of $30.97 \%$ which is comparable to what was reported in the study of Ma et $\mathrm{al}^{21}$ with frequencies ranging from $10.8 \%$ to $31.3 \%$ in Cameroon and that of Nkenfou et $\mathrm{al}^{20}$ with a frequency of $17.6 \%$ in the Western Region of Cameroon. Among other African populations, frequencies ranging from $10 \%-30 \%$ have been reported.

Table I Frequency And Distribution Of CCR2 Genotypes And Their Association With HIV Status

\begin{tabular}{|l|l|l|l|l|}
\hline CCR2 Genotypes & HIV Infected Children & $\begin{array}{l}\text { HIV Un-Infected Children } \\
\text { N=96 (\%) }\end{array}$ & $\begin{array}{l}\text { Total } \\
\text { N=134 (\%) }\end{array}$ & $\begin{array}{l}\text { HWE } \\
\mathbf{X}^{\mathbf{2}}, \mathbf{P}\end{array}$ \\
\hline G/G (wt/wt) & $15(39.48)$ & $45(46.88)$ & $60(44.78)$ & $2.91,0.09$ \\
G/A (wt/mut) & $20(52.63)$ & $45(46.88)$ & $65(48.5 \mathrm{I})$ \\
A/A (mut/mut) & $3(7.89)$ & $6(6.25)$ & $9(6.7 \mathrm{I})$ & \\
\hline
\end{tabular}

Abbreviations: wt, wildtype; mut, mutant; HWE, Hardy Weinberg Equilibrium. 
The frequencies of the CCR2-64I allele in African populations have been higher than what has been observed in Caucasians (7\%-10\%), while Asian populations show a wider range from $1 \%-30 \%{ }^{22}$ A study on subjects selected from different regions of Jordan showed that this allele is common among Jordanians, with a prevalence of $17.5 \%{ }^{8}$ The CCR2-64I mutation appears to be common in all ethnic groups, ${ }^{10}$ and the observation is in accordance with the theory that it is an ancient one. ${ }^{23}$ The CCR2-V64I mutation affects the function receptor on the outside of the cell. ${ }^{24}$ This may further impact disease acquisition and progression. CCR2 polymorphism is associated with risk of MTCT probably because of its role as an HIV-1 coreceptor or by modulating the early immune response. ${ }^{25}$ To evaluate the potential effect of CCR2-64I on HIV infection in this pediatric population, we compared its allelic frequency between the HIV non-infected group and the HIV infected group and no significance was found. The frequency was not significantly higher in HIV seropositive participants $(34.21 \%)$ than in the seronegative participants (29.69\%). This may imply that CCR2-64I do not protect against the infection in the pediatric population of the Cameroon Northern Region. This lack of association may explain in part the high MTCT rate in this part of the country. A study conducted in the Western Region of Cameroon (which has an HIV prevalence of 2.3\%) reported a CCR2-64I allele frequency of $17.62 \%$. The seronegative group showed a frequency $(18.7 \%)$ that was not significantly higher than that observed in seropositive ones $(12.5 \%)$. This result suggested that the CCR2-64I allele is not associated with HIV infection. Our result is comparable to that reported by Brouwer et $\mathrm{al}^{16}$ among Kenyan children. Their results did not indicate an effect of the allele of interest on perinatal HIV transmission. Another study carried out in a Guangxi Province population, a Chinese ethnic group, showed no significant difference in frequencies of CCR2-64I $\left(\mathrm{x}^{2}=1.795, \mathrm{p}=0.180\right)$ between the group of healthy individuals and the group of HIV-positive patients. ${ }^{17}$ Due to such controversial results, a meta-analysis carried out by Ding et al, ${ }^{26}$ aiming to clarify the relationship between the polymorphism of CCR2-V64I and the risk of HIV-1 infection also found that it has no effect on susceptibility to it in the total population. On the contrary, some studies reported a protective role of CCR2-64I in HIV MTCT. ${ }^{14,15}$ A possible mechanism of protection involves the CCR2 190A (64I) allele encoding a protein variant of the CCR2 receptor with increased affinity to dimerize with HIV co-receptor CXCR4 as compared to the CCR2 190G (64V) variant. The dimerization reduces the amount of CXCR4 available for HIV binding, therefore reducing the chances of
HIV entering the host cell. ${ }^{7}$ Scientists believe that the roles of CCR2-64I allele may differ in different populations because of variation in genetic backgrounds. Overall, this implies that HIV acquisition or protection may be an association of several factors.

The limit of our study is the lack of viral load data.

\section{Conclusion}

Our study found that there was no association between CCR2 polymorphism and HIV infection in children in Northern Cameroon. CCR2-64I does not seem to play a protective role in our population as shown in other studies. Can this thus explain the high transmission rate of HIV in this region? We suggest further investigations on: (a) other single nucleotide polymorphisms to determine their possible role in HIV infection in Northern Cameroon; and (b) whether lack of protection by $C C R 2$ may be a factor that increases the rate of MTCT in North Cameroon.

\section{Acknowledgements}

We acknowledge the participants of this study, and the Chantal Biya International Reference Centre (CBIRC) for providing the funding.

\section{Author contributions}

MNN: conception, design, sample collection, and manuscript preparation. CNN: conception, design, sample collection, and interpretation. BAT: conception, design, interpretation and manuscript preparation. LCMM, ENN and BD: Sample collection and interpretation. CK: Data interpretation and critical review of the manuscript. GNT: design and interpretation. WFM and AN: conception and design. All authors contributed towards data analysis, drafting and critically revising the paper, gave final approval of the version to be published, and agreed to be accountable for all aspects of the work.

\section{Disclosure}

The authors report no conflicts of interest in this work.

\section{References}

1. UNAIDS. Miles to go-closing gaps, breaking barriers, righting injustices. Global AIDS Update 2018. Available from: https://www. unaids.org/en/resources/documents/2018/global-aids-update. Accessed 11 March 2019

2. Penazzato M, Irvine C, Vicari M, et al. A global research agenda for pediatric HIV. J Acquir Immune Defic Syndr. 2018;78:S10-S15. doi:10.1097/QAI.0000000000001743 
3. UNAIDS. Global Report: UNAIDS Report on the Global AIDS Epidemic. 2012. Available from: https://www.unaids.org/sites/ default/files/media_asset/20121120_UNAIDS_Global_Report_2012_ with annexes en 1 .pdf. Accessed 11 March 2019.

4. UNAIDS. The Gap Report; 2014. Available from: http://files.unaids. org/en/media/unaids/contentassets/documents/unaidspublication/ 2014/UNAIDS_Gap_report_en.pdf. Accessed 8 April 2019.

5. Summary sheet: Preliminary findings. Cameroon Population-Based HIV-Impact Assessment; Camphia 2017. Available from: https://phia. icap.columbia.edu/wp-content/uploads/2018/07/3471CAMPHIA_ Cameroon-SS_A4_v13_requests_7.25.18.pdf. Accessed 25 July 2018.

6. Comité National de Lutte Contre le SIDA. Rapport de progrès PTME [Report of PMT Progress Number 12]; 2017. Available from: http:// www.cnls.cm/sites/default/files/rapport_progres_ptme_ndeg_12_ 2017_1.pdf. Accessed 12 February 2019. French.

7. Mhandire K, Duri K, Kandawasvika G, et al. CCR2, CX3CR1, RANTES and $S D F 1$ genetic polymorphisms influence HIV infection in a Zimbabwean pediatric population. $J$ Infect Dev Ctries. 2014;8 (10):1313-1321. doi:10.3855/jidc.4599

8. Khabour OF, Abu-Haweleh LJ, Alzoubi KH. Distribution of CCR5 $\triangle 32$, CCR2-64I, and SDF-1-3'A alleles among Jordanians. AIDS Res Hum Retrovirus. 2013;29(1):151-155. doi:10.1089/aid.2012.0107

9. Munerato P, Azevedo ML, Araripe Sucupira MC, et al. Frequency of polymorphisms of genes coding for HIV-1 co-receptors CCR5 and CCR2 in a Brazilian population. Br J Inf Dis. 2003;7(4):236-240.

10. Struyf F, Thoelen I, Charlier N, et al. Prevalence of CCR5 and CCR2 HIV-coreceptor gene polymorphisms in Belgium. Hum Hered. 2000;50(5):304-307. doi:10.1159/000022932

11. Mouafo Mekue LC, Dambaya B, Ngoufack MN, Nkenfou NC. Host molecular factors and viral genotypes in the mother to-child HIV-1 transmission in sub-Saharan Africa. J Pub Health Africa. 2017;8:594.

12. Cavarelli M, Scarlatti G. HIV-1 co-receptor usage: influence on mother to-child transmission and pediatric infection. $J$ Translat Med. 2010;9(Suppl 1):S10. doi:10.1186/1479-5876-9-S1-S10

13. Teglas JP, N'Go N, Burgard M, et al. CCR2B-64I chemokine receptor allele and mother-to-child HIV-1 transmission or disease progression in children. J Acquir Immune Defic Syndr. 1999;22:267-271. doi:10.1097/00042560-199911010-00008

14. Mangano A, Kopka J, Batalla M, Bologna R, Sen L. Protective effect of CCR2-64I and not of CCR5-delta32 and SDF1-3'A in pediatric HIV-1 infection. J Acquir Immune Defic Syndr. 2000;23(1):52-57. doi:10.1097/00042560-200001010-00007

15. Mabuka J, Mackelprang RD, Lohman-Payne B, et al. CCR2-64I polymorphism is associated with lower maternal HIV-1viral load and reduced vertical HIV-1 transmission. J Acquir Immune Defic Syndr. 2009;51(2):235-237. doi:10.1097/QAI.0b013e31819c155b
16. Brouwer KC, Yang C, Parekh S, et al. Effect of CCR2 chemokine receptor polymorphism on HIV type 1 mother to-child transmission and child survival in Western Kenya. AIDS Res Hum Retroviruses. 2005;21:358-362. doi:10.1089/aid.2005.21.358

17. Su Q, Mai Z, Zang N, Wu S, Xiao X, Liang H. Distribution of CCR5D32, CCR2-64I, and SDF1-3'A in Guangxi Zhuang Population. $J$ Internat Assoc Physicians AIDS Care. 2010;e9(3):145-149.

18. Chang J, Omuomo K, Anyango E, et al. Field evaluation of Abbott Real Time HIV-1 Qualitative test for early infant diagnosis using dried blood spots samples in comparison to Roche COBAS Ampliprep/COBAS TaqMan HIV-1 Qual Test in Kenya. $J$ Virol Methods. 2014;204:25-30. doi:10.1016/j.jviromet.2014.03.010

19. Huang S, Erickson B, Mak WB, Salituro J, Abravaya K. A novel RealTime HIV-1 Qualitative assay for the detection of HIV-1 nucleic acids in dried blood spots and plasma. $J$ Virol Methods. 2011;178:216-224. doi:10.1016/j.jviromet.2011.09.015

20. Nkenfou NC, Mouafo Mekue LC, Tafou NC, Kuiate JR. Distribution of CCR5-Delta32, CCR5 promoter 59029 A/G, CCR2-64I and SDF13'A genetic polymorphisms in HIV-1 infected and uninfected patients in the West Region of Cameroon. BMC Res Notes. 2013;6:288.2-5. doi:10.1186/1756-0500-6-288

21. Ma L, Marmor M, Zhong P, Ewane L, Su B, Nyambi P. Distribution of CCR2-64I and SDF1-3'A alleles and HIV status in 7 ethnic populations of Cameroon. J Acquir Immune Defic Syndr. 2005;40 (1):89-95. doi:10.1097/01.qai.0000157008.66584.d6

22. Bharti D, Kumar A, Mahla RS, et al. Low prevalence of CCR5- $\Delta 32$, CCR2-64I and SDF1-3'A alleles in the Baiga and Gond tribes of Central India. Springer Plus. 2015;4:451. doi:10.1186/s40064-0151238-6

23. Acosta AX, Sampaio RG, Spínola JL, Galvão-Castro B. Distribution of the CCR2-64I allele in three Brazilian ethnic groups. Gen Molec Biol. 2003;26(3):241-243.

24. Wachira D, Lihana R, Okoth V, Maiyo A, Khamadi SA. Chemokine coreceptor-2 gene polymorphisms among HIV-1 infected individuals in Kenya. Dis Markers. 2015;ID952067, 4.

25. Singh KK, Hughes MD, Chen J, et al. Associations of chemokine receptor polymorphisms with HIV-1 mother-to-child transmission in sub-Saharan Africa: possible modulation of genetic effects by antiretrovirals. $J$ Acquir Immune Defic Syndr. 2008;49:259-265. doi:10.1097/QAI.0b013e318186eaa4

26. Ding DL, Liu SJ, Zhu HZ. Association between the CCR2-Val64Ile polymorphism and susceptibility to HIV-1 infection: a meta-analysis. Molec Med Rep. 2011;4:181-186.

\section{Publish your work in this journal}

The Application of Clinical Genetics is an international, peerreviewed open access journal that welcomes laboratory and clinical findings in the field of human genetics. Specific topics include: Population genetics; Functional genetics; Natural history of genetic disease; Management of genetic disease; Mechanisms of genetic disease;
Counselling and ethical issues; Animal models; Pharmacogenetics; Prenatal diagnosis; Dysmorphology. The manuscript management system is completely online and includes a very quick and fair peerreview system, which is all easy to use. Visit http://www.dovepress. com/testimonials.php to read real quotes from published authors. 